\title{
RACE-ETHNICITY IN EUROPE
}

\section{Researching race-ethnicity in race-mute Europe}

\author{
Philipp Jugert, Marie J. Kaiser, Francesca Ialuna, \& Sauro Civitillo \\ University of Duisburg-Essen
}

Version Date: June 7, 2021

In press, Infant and Child Development

\begin{abstract}
Author Note
Philipp Jugert (D) https://orcid.org/0000-0003-4313-0596

Sauro Civitillo (D) https://orcid.org/0000-0001-7607-0935

Francesca Ialuna(iD https://orcid.org/0000-0002-2159-7198

We have no known conflict of interest to disclose.

Correspondence concerning this article should be addressed to Philipp Jugert,

Department of Psychology, University of Duisburg-Essen, Universitätsstr. 2, 45141 Essen, Germany. Email: philipp.jugert@uni-due.de.
\end{abstract}




\title{
RACE-ETHNICITY IN EUROPE
}

\begin{abstract}
In Germany and continental Europe more broadly, race and ethnicity are concepts that are not widely used and increasingly erased from legislation. Nevertheless, race and ethnicity are still used as social markers and often merely replaced with other terms (e.g., cultural background). The goal of this paper is threefold. First, we point to the danger of treating race and ethnicity as essentialist categories, which is still common in developmental science research. Second, we want to outline specific problems that occur when doing research on ethnicity and race with children and adolescents in the European race-mute context. Third, we suggest that future research ought to focus more on constructions of Whiteness and reproduction of power differences among ethnic majority populations. In doing so, we draw on examples from our own research on ethnic-racial identity and ethnic-racial socialization.
\end{abstract}




\section{RACE-ETHNICITY IN EUROPE}

"Race does not exist but it does kill people” (Guillaumin, 2002; p. 107)

Suppose, a developmental psychologist wants to conduct a study on depressive symptoms in a sample of ethnically and culturally diverse youth attending the same school. Should they assume a priori that race or ethnicity matter for this research question and therefore attempt to classify individuals into different racial or ethnic groups and compare them in depressive symptomology? If they were to conduct the study in Europe, what language would they use to ask participants about their race and ethnicity? If they had a theory that racial/ethnic identity development is related to depressive symptoms would they also ask White ethnic majority youth about their racial/ethnic identity development? In this paper, we point to a) the danger of treating race and ethnicity as essentialist categories, b) problems that occur when doing research on race and ethnicity with children and adolescents in the European context, and we suggest that c) future research ought to focus more on constructions of Whiteness and the reproduction of power differences among ethnic majority populations. In doing so, we will draw on examples from our own research. While the examples we use mostly cover the German context, these questions are relevant in other Northern (e.g., Sweden) and Western (e.g., France) European countries as well, which share a similar reluctance to use race and ethnicity (cf. Roig, 2017). Before tackling these questions, we need to clarify what we mean by race and ethnicity and related constructs.

\section{Words Matter: Defining Race, Ethnicity, and Related Constructs}

Race and ethnicity are highly controversial terms and there is no consensually shared definition of these terms. Race can be defined as "a characterization of a group of people believed to share physical characteristics such as skin color, facial features, and other hereditary traits", while ethnicity can be defined as "a characterization of a group of people who see themselves and are seen by others as having a common ancestry, shared history, shared traditions, and shared cultural traits such as language, beliefs, values, music, dress, and food" (Cokley, 2007; p. 225). We conceive of race and ethnicity as social constructions that 


\section{RACE-ETHNICITY IN EUROPE}

lack any meaningful biological basis (Bhopal, 2004). In contrast, a biological or essentialist understanding of race and ethnicity assumes that there are natural differences in intelligence and aptitude between individuals from different racial or ethnic groups. Thus, when for example certain racial or ethnic groups (e.g., Blacks in the US or Turkish-origin youth in Germany) underperform in standardized tests, such a view will see these results as proof that these groups are innately less capable. Instead, a view of race and ethnicity as social constructions acknowledges that race and ethnicity are not innate properties of individuals but social inventions that often serve to establish racial hierarchies and White dominance (Markus, 2008). Such a view will consider historical and structural differences in access to education when trying to explain racial or ethnic differences in educational achievement. It also acknowledges that race and ethnicity are fluid and changing social categories that differ across historical (e.g., Irish and Italians were once considered racial groups in the US) and geographical contexts (e.g., who is considered to be Black or White differs across countries and even within countries (Gjerde, 2014)). Viewing race and ethnicity as social constructions also acknowledges that race and ethnicity can refer to individuals who self-ascribe (i.e., identify) to these groups and to individuals who are merely ascribed to certain groups by others (e.g., a child may identify as German but is ascribed an ethnic minority background by their peers due to phenotype).

While it is possible to come up with separate definitions for race and ethnicity, they are overlapping concepts (e.g., individuals can have both race and ethnicity, such as Black Caribbean) that are often used interchangeably, and in Europe race has been almost completely abandoned in favour of ethnicity (Bhopal, 2004). The interrelated nature of race and ethnicity and the fact that different terminology is used to refer to similar psychological processes is reflected in the development of meta-constructs like ethnic-racial identity (ERI; Umaña-Taylor et al., 2014) and ethnic-racial socialisation (ERS; Hughes et al., 2006). ERI refers to "the beliefs and attitudes that individuals have about their ethnic-racial group 


\section{RACE-ETHNICITY IN EUROPE}

memberships, as well as the processes by which these beliefs and attitudes develop over time" (Umaña-Taylor et al., 2014; p. 23) and acknowledges that youth do not keep separate the racial from the ethnic components of their identity. ERS refers to the transmission from adults to children of information regarding race and ethnicity (Hughes et al., 2006). The bulk of research on ERI and ERS has been conducted in the US and it is therefore less clear how these constructs can be applied to different cultural contexts (cf. Juang et al., in press). For instance, Markus (2008) argued that race and ethnicity differ in that individuals have more say in defining their ethnicity than their race. While this may be true in the US, this assertion may be less applicable in Europe where race is rarely used and ethnicity does not necessarily grant individuals more power in self-definition as illustrated by the example above of discrepancies between how individuals may see themselves in ethnic terms and how they are seen by others.

While White refers to a racial category, Whiteness is seldomly defined, but in our view, it examines the "White experience" or what it means to be White vis-à-vis societal contexts where being White almost always means to be relatively more privileged and powerful compared to non-White racial-ethnic minority groups (Lewis, 2004). One of these privileges is that for a long time only racial-ethnic minority individuals were thought to have race (e.g., Blackness), while Whites were just considered "normal". As White is not commonly used in Germany and most European countries, we use the terms White and ethnic majority interchangeably.

Migration background was a term introduced into the German census in 2005 in order to advance the previous crude differentiation between individuals with and without German citizenship. Individuals are classified as having a migration background if they themselves or at least one of their parents has received German citizenship not by birth (DESTATIS Statistisches Bundesamt, 2019, p. 4). The term is also used in other Continental European countries and, in Germany, this group comprises a very heterogeneous group, consisting of 25 $\%$ of the overall population. 


\section{RACE-ETHNICITY IN EUROPE}

\section{Ethnicity and race are not "out there"}

In this section, we will point to the danger of treating race and ethnicity as essentialist categories. Although we are certainly not the first to make this point (cf. Gjerde, 2014; Helms et al., 2005; Markus, 2008) there is a risk of treating ethnicity and race as natural kinds that are "out there". Unfortunately, psychologists tend to be "analytic naturalizers" rather than “analysts of naturalizers" (Gil-White, 1999), meaning that they take group differences between social categories (e.g., race and ethnicity) for granted rather than studying the social construction of these categories in their own right. Different approaches can be found in neighbouring disciplines such as sociology and educational sciences. An important perspective in this regard is the idea of ethnic boundary making (Wimmer, 2008), which suggests that it is necessary to study for a particular research context whether ethnicity is relevant and if so how it is constructed by individuals. Relatedly, Brubaker (2004) suggests that race and ethnicity are fluid and changing subjective constructions rather than objective facts.

In our own research we have examined the role of subscribed (e.g., ethnic selfcategorization) rather than ascribed (e.g., based on parents' country of origin) definitions of ethnic group membership for ethnic minority adolescents. We could show that these ethnic self-categorizations were relevant for friendship choices among adolescents in ethnically diverse schools, beyond ascribed ethnic group membership (Jugert et al., 2018). In this study, we also found that between 20 and $60 \%$ of ethnic self-identification choices varied within individuals across time. In other words, an ethnic minority adolescent may choose to selfidentify as German on one measurement occasion, but switch to a dual identification on another occasion. In the US, one study showed that over $20 \%$ of adolescents varied in their ethnic self-identifications across time (Nishina et al., 2018). These results underscore the importance of treating race and ethnicity as fluid self-constructions rather than stable objective markers of group membership. We note that ethnic self-identification may also vary 


\section{RACE-ETHNICITY IN EUROPE}

by developmental phase (e.g., childhood, adolescence, emerging adulthood) and context (e.g., family or school).

\section{Challenges in race and ethnicity research in Europe}

In this section, we will point to problems that occur when doing research on race and ethnicity with children and adolescents in the European race-mute context. One of the major practical problems for researchers in continental Europe who are interested in issues of race and ethnicity is finding the right terminology when designing interview schedules or questionnaire items. Why is this? Both in Germany and in Western and Northern Europe there is a "silence about race" in both political and social discourse (Lentin, 2008; Roig, 2017). The reluctance to use race is related to WWII history, and the discourse of overcoming the past of the national-socialist racist ideology and the Holocaust in today's egalitarian societies. This denies the continuity between pre-war colonial history of many European countries and the deeply embedded everyday racism at the core of society (Roig, 2017). Instead, racism is mostly used to describe the acts of a minority of right-wing extremists (e.g., perpetrators of mass shootings targeting ethnic and religious minorities), creating "false binaries" (Diangelo, 2018) between the alleged majority of tolerant good people and a minority of bad racists. But individuals do not cease to use markers of difference, they just use other terms.

In Germany as in many other European countries, national and ethnic boundaries are blurred and difficult to separate for ethnic majority individuals. This makes it very difficult to distinguish both conceptually and empirically between notions like nationality, ethnicity, and culture (Ditlmann et al., 2011; Mecheril, 2003). As a consequence, words like race and ethnicity are not anchored in public discourse and are instead replaced with words like culture, migration background or country of origin (Moffitt et al., 2020). Researchers are left to wonder how to address race and ethnicity and the importance they have in everyday life with their participants, particularly with children and adolescents who may have never heard of these terms. 


\section{RACE-ETHNICITY IN EUROPE}

Getting back to the example of the researcher attempting to do a study on depressive symptoms, we make some suggestions for how researchers may address these issues in the European context, but also want to raise some unresolved problems. First, researchers should examine whether race or ethnicity are even relevant in the context of their study. All too often, developmental scientists blindly assume that there will be racial or ethnic group differences in a given outcome variable (e.g., delinquency or depression) without considering the possibility that social groups are often more similar than different from each other (cf. Hanel et al., 2019). However, without a guiding theory about why we should expect racial/ethnic group differences in a particular outcome variable these group comparisons run the risk of producing spurious group differences and result in ad-hoc and post-hoc interpretations of these group differences (Syed, 2020). Relatedly, racial/ethnic group differences are uninformative if they cannot be explained by meaningful psychological process variables (e.g., racial-ethnic self-categorization, language proficiency, socioeconomic resources, etc.). This is well known in cultural psychology and exemplified in the idea of cultural unpackaging (Heine, 2020): the identification of underlying variables that create cultural differences (e.g., independent vs. interdependent self-construal). A good example is a study by Juang and Syed (2010) who showed that when adding family cultural socialization as a predictor of ethnic identity, ethnicity was no longer a significant predictor. Another possibility is to include general developmental processes (e.g., age-related changes) to explain variance in outcome variables (e.g., victimization), which may show that these agerelated changes are more relevant than immigration-related variables (e.g., Jugert \& Titzmann, 2017).

Second, researchers should avoid static markers of race and ethnicity and labels that are exclusively based on ascribed criteria such as individuals' and their parents' country of origin. In particular, the term migration background should be abandoned (cf. Fachkommission Integrationsfähigkeit, 2020), because it has been shown that a majority of 


\section{RACE-ETHNICITY IN EUROPE}

individuals classified as such do not identify with this category (Nesterko \& Glaesmer, 2019). The term migration background does not help to make social exclusion and racial discrimination visible because these can also affect non-White individuals without migration background (e.g., ethnic minority members), while individuals with migration background who are read as White may be unaffected (Fachkommission Integrationsfähigkeit, 2020).

We think that it is important to distinguish more clearly between immigrants (i.e., those who immigrated themselves) and ethnic minority individuals who may be descendants of immigrants. The latter group may not identify only as members of an ethnic minority anymore. At present, these boundaries often get blurred by using terms like migration or immigrant background in the European context when applied to individuals who did not immigrate themselves. By ascribing markers of ethnic group membership to individuals without giving participants a choice in this, developmental scientists contribute to discourses about "perpetual foreigners" and identity denial (Cheryan \& Monin, 2005). Thus, we think it is useful to ask for individuals' ethnic-racial self-identification, in addition to ascribed markers of ethnic group membership. This can be done by using open-ended questions, and because of participants' unfamiliarity with concepts like race/ethnicity in Europe, it may necessitate to provide instructions like "Everyone has an ethnic belonging. A person can have more than one ethnic identity. Examples of ethnic identities are X, Y, and Z [to be populated with relevant ethnic groups in a particular context]. Every person decides his or her ethnic belonging” (Gyberg et al., 2021; p. 168). In fact, in recent studies we classified a sizeable number of adolescents as having no ethnic minority background if this reflected their selfidentification (e.g., if they self-identified as German), irrespective of their ascribed ethnic group membership (Civitillo, Göbel, et al., 2021; Jugert et al., 2018, 2020; Vietze et al., 2021).

However, we acknowledge that using ethnic/racial self-identification to classify participants is not a panacea to the problem of how to classify individuals into groups. For this 


\section{RACE-ETHNICITY IN EUROPE}

reason, third, one should not assume that these classifications are stable across time within individuals because of the fluid and dynamic nature of ethnic/racial self-identifications that may vary within and between individuals across time and context. This may be particularly important for children and adolescents in the process of identity development. In fact, selfcategorization theory (Turner et al., 1987) would predict that individuals will vary in terms of how salient certain group identities are depending on situational context. This needs to be better reflected in our methodological toolkits. Yearly assessments of ethnic self-identification that are common in many longitudinal studies (and which we have used ourselves) are suboptimal to understand how children and adolescents develop their ERI because they cannot capture moment-to-moment changes in expressions and feelings about ERI depending on contextual features (e.g., home vs. school environment). Thus, future research should make greater use of experience sampling methods that measure constructs daily or even multiple times per day that are better able to grasp within-person variance in these constructs (see Yip et al., 2020 for a review of these methods in the context of research on ERI).

What is more difficult is to find the right terminology when addressing these issues with participants in the European race-mute context. We would like to point out that this is not just relevant for quantitative, but also for qualitative research. In a qualitative study on ERS among White German parents, it proved to be very difficult to find common understandings of race and ethnicity in German that do not reproduce problematic discourses (Kaiser, in preparation). A real danger here is that by using terms thought to be readily understandable to children and adolescents, researchers may unintentionally reproduce othering discourses prevalent in society with as yet unclear consequences for reliability and validity of the employed measures. For example, in one study (Jugert et al., 2011) we asked $5^{\text {th }}$ grade children about equal treatment by teachers by having them rate statements like "All children in this class are treated equal no matter what country they are from." Similar item formulations have been used in other studies (e.g., "our teachers are equally friendly with 


\section{RACE-ETHNICITY IN EUROPE}

German and foreign children"; Schachner et al., 2016). In both examples a distinction is made between native German children and foreign children despite the fact that most of these children will not have immigrated themselves but are descendants of immigrants (sometimes across multiple generations). Others (including ourselves) have replaced ethnic-racial identity with heritage culture identity (Juang et al., 2020) or cultural origin (Schotte et al., 2018) identity or replaced "race" with "cultural background" (Civitillo, Juang, \& Schachner, 2021). We have no easy answers to this problem, but we do want to raise the issue whether such adaptations are problematic in their own right because existing race-related inequities are not captured when avoiding terms like race or skin colour, and replacement terms like cultural background are often racialized and used to refer only to visible ethnic minority individuals (Civitillo, Juang, \& Schachner, 2021).

\section{What about White children's ethnic and racial identities?}

In the last section, we point to the need for future research to focus more on constructions of Whiteness and reproduction of power differences among ethnic majority populations. While research on ERI has been flourishing in recent years, the bulk of studies has focused on how ethnic minority children and adolescents develop their ethnic, bi-, or tricultural identities. However, a large research gap exists with regard to how White ethnic majority children and adolescents develop their ERI (Loyd \& Gaither, 2018). First results from a qualitative study on racial-ethnic socialization goals of White German parents suggest that, similar to the US (Bartoli et al., 2016; Hagerman, 2014; Underhill, 2018), colourblindness, i.e. the reluctance to discuss topics related to race and racism or perpetuating ideas that race does not matter, were a prominent feature. Parents hardly showed any awareness of power privileges afforded to them by their position as White in a structurally racist system (Kaiser, in preparation). Thus, White people are doing race, ethnicity and culture on a daily basis, too, even if their majority status position may allow them to refrain from conscious reflection about it (Markus \& Moya, 2010). This power dynamic is often reflected in 


\section{RACE-ETHNICITY IN EUROPE}

psychological research where only the behaviour of ethnic minority individuals is attributed to culture (Causadias et al., 2018). Promising directions are first studies that examine ERI exploration among ethnic majority adolescents (Juang et al., 2020; Spiegler et al., 2021) but we need more research examining how ethnic majority youth conceptualize their ethnic and racial identities vis-à-vis a context that delegates identity work to immigrants and their descendants under the framework of "integration" (Moffitt et al., 2020). Of course, this should not undermine empowering research on racialized groups and the pernicious consequences of discrimination but be seen as an important complementary missing puzzle to better understand and overcome racial and ethnic inequalities.

\section{Conclusion}

So, what should the developmental psychologist who wants to conduct a study on depressive symptoms in a sample of ethnically and culturally diverse youth do? First, as with any research, appropriate grounding in theory is essential. If there is a good theoretical rationale for assuming that race/ethnicity plays a role, then this should be examined. But it should be kept in mind that racial/ethnic group differences are not informative in and of themselves and should therefore be unpackaged with the use of psychological process variables. Second, they should acknowledge the fluidity and social constructedness of race and ethnicity by using operationalizations of race/ethnicity that do not exclusively rely on ascribed criteria and also include individuals' ethnic-racial self-identification. Third, fluidity of race/ethnicity should be reflected in appropriate methods such as mixed-method or experience-sampling designs. Fourth, when examining race/ethnicity in contexts like Europe where these terms are not used, it may be necessary to adapt terminology in ways that reflect the concepts, but also think closely about how to avoid othering and identity-denial. Finally, more research is needed on White children and adolescents and how they become socialized into doing race/ethnicity in structurally racist societies. 


\section{RACE-ETHNICITY IN EUROPE}

\section{References}

Bartoli, E., Michael, A., Bentley-Edwards, K. L., Stevenson, H. C., Shor, R. E., \& McClain, S. E. (2016). Training for colour-blindness: white racial socialisation. Whiteness and Education, 1(2), 125-136. https://doi.org/10.1080/23793406.2016.1260634

Bhopal, R. (2004). Glossary of terms relating to ethnicity and race: For reflection and debate. Journal of Epidemiology and Community Health, 58(6), 441-445.

https://doi.org/10.1136/jech.2003.013466

Brubaker, R. (2004). Ethnicity without groups. Harvard Unversity Press.

Causadias, J. M., Vitriol, J. A., \& Atkin, A. L. (2018). Do we overemphasize the role of culture in the behavior of racial/ethnic minorities? Evidence of a cultural (mis)attribution bias in American psychology. The American Psychologist, 73(3), 243-255. https://doi.org/10.1037/amp0000099

Cheryan, S., \& Monin, B. (2005). "Where are you really from?": Asian Americans and identity denial. Journal of Personality and Social Psychology, 89(5), 717-730. https://doi.org/10.1037/0022-3514.89.5.717

Civitillo, S., Göbel, K., Preusche, Z., \& Jugert, P. (2021). Disentangling the effects of perceived personal and group ethnic discrimination among secondary school students: The protective role of teacher-student relationship quality and school climate: The protective role of teacher-student relationship quality and school climate. New Directions for Child and Adolescent Development. Advance online publication. https://doi.org/10.1002/cad.20415

Civitillo, S., Juang, L. P., \& Schachner, M. K. (2021). Stressing similarities or ignoring differences? Shedding light into different forms of color-evasive ideology with pre- and inservice teachers. Zeitschrift Für Erziehungswissenschaft, 24(1), 135-153. https://doi.org/10.1007/s11618-021-00995-9 


\section{RACE-ETHNICITY IN EUROPE}

Cokley, K. (2007). Critical issues in the measurement of ethnic and racial identity: A referendum on the state of the field. Journal of Counseling Psychology, 54(3), 224-234. https://doi.org/10.1037/0022-0167.54.3.224

DESTATIS - Statistisches Bundesamt. (2019). Bevölkerung und Erwerbstätigkeit. Bevölkerung mit Migrationshintergrund - Ergebnisse des Mikrozensus 2018. Fachserie 1: Reihe 2.2.

Diangelo, R. (2018). White fragility: Why it's so hard for White people to talk about racism. Beacon Press.

Ditlmann, R. K., Purdie-Vaughns, V., \& Eibach, R. P. (2011). Heritage- and ideology-based national identities and their implications for immigrant citizen relations in the United States and in Germany. International Journal of Intercultural Relations, 35(4), 395-405. https://doi.org/10.1016/j.ijintrel.2010.07.002

Fachkommission Integrationsfähigkeit. (2020). Shaping our immigration society together: Report of the Federal Government Expert Commission on the framework for sustainable integration. Report of sustainable intergration_Fachkomission englisch-data.pdf

Gil-White, F. J. (1999). How thick is blood? The plot thickens. .: if ethnic actors are primordialists, what remains of the circumstantialist / primordialist controversy? Ethnic and Racial Studies, 22(5), 789-820. https://doi.org/10.1080/014198799329260

Gjerde, P. F. (2014). An Evaluation of Ethnicity Research in Developmental Psychology: Critiques and Recommendations. Human Development, 57(4), 176-205. https://doi.org/10.1159/000362768

Guillaumin, C. (2002). Racism, sexism, power and ideology. Routledge.

Gyberg, F., Svensson, Y., Wängqvist, M., \& Syed, M. (2021). Discrimination and its relation to psychosocial well-being among diverse youth in Sweden. New Directions for Child and Adolescent Development, 2021(176), 163-181. https://doi.org/10.1002/cad.20399 


\section{RACE-ETHNICITY IN EUROPE}

Hagerman, M. A. (2014). White families and race: colour-blind and colour-conscious approaches to white racial socialization. Ethnic and Racial Studies, 37(14), 2598-2614. https://doi.org/10.1080/01419870.2013.848289

Hanel, P. H. P., Maio, G. R., \& Manstead, A. S. R. (2019). A new way to look at the data: Similarities between groups of people are large and important. Journal of Personality and Social Psychology, 116(4), 541-562. https://doi.org/10.1037/pspi0000154

Heine, S. H. (2020). Cultural Psychology (4th ed.). Norton \& Co.

Helms, J. E., Jernigan, M., \& Mascher, J. (2005). The meaning of race in psychology and how to change it: A methodological perspective. The American Psychologist, 60(1), 27-36. https://doi.org/10.1037/0003-066X.60.1.27

Hughes, D., Rodriguez, J., Smith, E. P., Johnson, D. J., Stevenson, H. C., \& Spicer, P. (2006). Parents' ethnic-racial socialization practices: A review of research and directions for future study. Developmental Psychology, 42(5), 747-770. https://doi.org/10.1037/00121649.42.5.747

Juang, L. P., Moffitt, U., Schachner, M. K., \& Pevec, S. (in press). Understanding ethnicracial identity in a context where "race" is Taboo. Identity.

Juang, L. P., Schachner, M. K., Pevec, S., \& Moffitt, U. (2020). The Identity Project intervention in Germany: Creating a climate for reflection, connection, and adolescent identity development. New Directions for Child and Adolescent Development, 2020(173), 65-82. https://doi.org/10.1002/cad.20379

Juang, L. P., \& Syed, M. (2010). Family cultural socialization practices and ethnic identity in college-going emerging adults. Journal of Adolescence, 33(3), 347-354. https://doi.org/10.1016/j.adolescence.2009.11.008 


\section{RACE-ETHNICITY IN EUROPE}

Jugert, P., Leszczensky, L., \& Pink, S. (2018). The Effects of Ethnic Minority Adolescents' Ethnic Self-Identification on Friendship Selection. Journal of Research on Adolescence, 28(2), 379-395. https://doi.org/10.1111/jora.12337

Jugert, P., Leszczensky, L., \& Pink, S. (2020). Differential Influence of Same- and CrossEthnic Friends on Ethnic-Racial Identity Development in Early Adolescence. Child Development, 91(3), 949-963. https://doi.org/10.1111/cdev.13240

Jugert, P., Noack, P., \& Rutland, A. (2011). Friendship preferences among German and Turkish preadolescents. Child Development, 82(3), 812-829. https://doi.org/10.1111/j.1467-8624.2010.01528.x

Jugert, P., \& Titzmann, P. F. (2017). Trajectories of victimization in ethnic diaspora immigrant and native adolescents: Separating acculturation from development. Developmental Psychology, 53(3), 552-566. https://doi.org/10.1037/dev0000254

Kaiser, M. J. (in preparation). White German parents and the socialization of ethnic-nationalcultural belongings in East Germany. Manuscript in Preparation.

Lentin, A. (2008). Europe and the Silence about Race. European Journal of Social Theory, 11(4), 487-503. https://doi.org/10.1177/1368431008097008

Lewis, A. E. (2004). "What Group?" Studying Whites and Whiteness in the Era of "ColorBlindness”. Sociological Theory, 22(4), 623-646. https://doi.org/10.1111/j.07352751.2004.00237.x

Loyd, A. B., \& Gaither, S. E. (2018). Racial/ethnic socialization for White youth: What we know and future directions. Journal of Applied Developmental Psychology, 59, 54-64. https://doi.org/10.1016/j.appdev.2018.05.004

Markus, H. R. (2008). Pride, prejudice, and ambivalence: Toward a unified theory of race and ethnicity. The American Psychologist, 63(8), 651-670. https://doi.org/10.1037/0003066X.63.8.651 


\section{RACE-ETHNICITY IN EUROPE}

Markus, H. R., \& Moya, P. M. L. (Eds.). (2010). Doing race: 21 essays for the 21 st century. W. W. Norton.

Mecheril, P. (2003). Prekäre Verhältnisse: Über natio-ethno-kulturelle (Mehrfach-) Zugehörigkeit [Precarious States: About national-ethnic-cultural (multiple) belongings]. Waxmann.

Moffitt, U., Juang, L. P., \& Syed, M. (2020). Intersectionality and Youth Identity Development Research in Europe. Frontiers in Psychology, 11, 78. https://doi.org/10.3389/fpsyg.2020.00078

Nesterko, Y., \& Glaesmer, H. (2019). Warum fragen wir nicht direkt nach? Psychologische Rundschau, 70(2), 101-108. https://doi.org/10.1026/0033-3042/a000399

Nishina, A., Bellmore, A., Witkow, M. R., Nylund-Gibson, K., \& Graham, S. (2018). Mismatches in Self-Reported and Meta-Perceived Ethnic Identification across the High School Years. Journal of Youth and Adolescence, 47(1), 51-63. https://doi.org/10.1007/s10964-017-0726-0

Roig, E. (2017). Uttering "race" in colorblind France and post-racial Germany. In K. Fereidooni \& M. El (Eds.), Rassimuskritik und Widerstandsformen [race critique and forms of resistance] (pp. 613-627). Springer. https://doi.org/10.1007/978-3-658-147211_36

Schachner, M. K., Noack, P., van de Vijver, F. J. R., \& Eckstein, K. (2016). Cultural Diversity Climate and Psychological Adjustment at School-Equality and Inclusion Versus Cultural Pluralism. Child Development, 87(4), 1175-1191. https://doi.org/10.1111/cdev.12536

Schotte, K., Stanat, P., \& Edele, A. (2018). Is Integration Always most Adaptive? The Role of Cultural Identity in Academic Achievement and in Psychological Adaptation of Immigrant 


\section{RACE-ETHNICITY IN EUROPE}

Students in Germany. Journal of Youth and Adolescence, 47(1), 16-37.

https://doi.org/10.1007/s10964-017-0737-X

Spiegler, O., Christ, O., \& Verkuyten, M. (2021). National identity exploration attenuates the identification-prejudice link. Group Processes \& Intergroup Relations. Advance online publication. https://doi.org/10.1177/1368430221990093

Syed, M. (2020). Whither the "white control group"? On the benefits of a comparative ethnic minority psychology. https://psyarxiv.com/n4p73

Turner, J. C., Hogg, M. A., Oakes, P. J., Reicher, S. D., \& Wetherell, M. S. (1987).

Rediscovering the social group: A self-categorization theory. Basil Blackwell.

Umaña-Taylor, A. J., Quintana, S. M., Lee, R. M., Cross, W. E., Rivas-Drake, D., Schwartz, S. J., Syed, M., Yip, T., \& Seaton, E. (2014). Ethnic and racial identity during adolescence and into young adulthood: An integrated conceptualization. Child Development, 85(1), 21-39. https://doi.org/10.1111/cdev.12196

Underhill, M. R. (2018). Parenting during Ferguson: making sense of white parents' silence. Ethnic and Racial Studies, 41(11), 1934-1951.

https://doi.org/10.1080/01419870.2017.1375132

Vietze, J., Schwarzenthal, M., Moffitt, U., \& Civitillo, S. (2021). Beyond 'Migrant Background': How to Select Relevant, Social Justice Oriented, and Feasible Social Categories in Educational Research. https://doi.org/10.31234/osf.io/j8f4r

Wimmer, A. (2008). The Making and Unmaking of Ethnic Boundaries: A Multilevel Process Theory. American Journal of Sociology, 113(4), 970-1022. https://doi.org/10.1086/522803

Yip, T., Mi Cheon, Y., \& Ehrhardt, A. (2020). Applying experience-sampling methods to investigate the impact of school diversity on youth development in multicultural contexts. In P. F. Titzmann \& P. Jugert (Eds.), Youth in superdiverse societies: Growing up with globalization, diversity, and acculturation (pp. 111-128). Routledge. 
RACE-ETHNICITY IN EUROPE 